Fast transport from Southeast Asia boundary layer sources to northern Europe: rapid uplift in typhoons and eastward eddy shedding of the Asian monsoon anticyclone

B. Vogel et al.

Correspondence to: B. Vogel (b.vogel@fz-juelich.de) 


\title{
Fast transport from Southeast Asia boundary layer sources to Northern Europe: Rapid uplift in typhoons and eastward eddy shedding of the Asian monsoon anticyclone
}

\author{
B. Vogel ${ }^{1}$, G. Günther ${ }^{1}$, R. Müller ${ }^{1}$, J.-U. Grooß ${ }^{1}$, P. Hoor ${ }^{2}$, M. Krämer ${ }^{1}$, S. Müller ${ }^{2}$, A. Zahn ${ }^{3}$, and M. Riese ${ }^{1}$ \\ ${ }^{1}$ Forschungszentrum Jülich, Institute of Energy and Climate Research - Stratosphere (IEK-7), Jülich, Germany \\ ${ }^{2}$ Institute for Atmospheric Physics, University of Mainz, Mainz, Germany \\ ${ }^{3}$ Institute for Meteorology and Climate Research, Karlsruhe Institute of Technology, Karlsruhe, Germany \\ Correspondence to: Bärbel Vogel \\ (b.vogel@fz-juelich.de)
}

\section{Supplementary material}

\subsection{0-day backward trajectories}

40-day backward trajectories starting at the observation ${ }_{35}$ along the flight path (every 10 seconds) on 26 September

52012 and ending at the origin of the air masses in the past (17 August 2012) were calculated. The potential temperature at the air mass origin $\left(\Theta_{\text {org }}\right)$ provides information about the vertical transport of the air mass along the trajectory. Transport pathways of air masses originating in intervals for $\Theta_{\text {org }}$ between $360 \mathrm{~K}-370 \mathrm{~K}, 370 \mathrm{~K}-380 \mathrm{~K}$, and $380 \mathrm{~K}-420 \mathrm{~K}$ are 40 shown in Figures 1 and 2.

Most air masses originate at $\Theta_{\text {org }}$ values between $360 \mathrm{~K}$ and $370 \mathrm{~K}$ (Fig. 1) experienced a moderately rapid uplift with mean values of about $2 \mathrm{~K} /$ day $(=22 \mathrm{hPa}$ /day) roughly in the masses originate mainly in North Africa, South Asia, and in the West Pacific. The trajectories had been separated from the anticyclone approximately $8-14$ days before the flight on 26 September 2012, and therefore transport air masses from inside the Asian monsoon anticyclone to Northern Europe. 50

At higher levels, for $\Theta_{\text {org }}$ between $370 \mathrm{~K}$ and $380 \mathrm{~K}$ (Fig. 1), the trajectories are affected by both the Asian monsoon anticyclone and the subtropical westerly jet. The moderate uplift along the trajectories amounts to in average $1 \mathrm{~K} /$ day ( $16 \mathrm{hPa}$ /day). The majority of air masses originate in re- 55 gions around the Asian monsoon anticyclone and in Central America. In the latter case, the trajectories are most likely affected by the North American monsoon.

Most air masses originating at $\Theta_{\text {org }}$ between $380 \mathrm{~K}$ and patterns with a descent of air masses into the Northern Hemisphere lower stratosphere. These trajectories do not circulate around the Asian monsoon anticyclone (except for two trajectories) and the air mass origins are spread throughout in the northern extratropical stratosphere, excluding regions affected by the Asian monsoon anticyclone such as South Asia or parts of North Africa.

\subsection{0-day backward trajectories}

A non-negligible fraction of the parcels (12\%) in the region of interest (cf. Sect. 2 main body of the paper) is also transported from the Asian monsoon region towards Northern Europe. In order to assess the geographical origin of these air parcels in the boundary layer, we calculated backward trajectories further beyond the 40-day limit. For this purpose, 60-day backward trajectories were calculated, a common trajectory length to study transport processes in the Asian monsoon region ranging from a couple of weeks to a few months.

For the region of interest, the origins of 60-day backward trajectories coming from low levels of potential temperature, from the $\Theta_{\text {org }}$ interval $285 \mathrm{~K}-320 \mathrm{~K}$, are clustered in Southeast Asia, West Pacific Ocean, Bay of Bengal, and the Arabian Sea. $53 \%$ of these trajectories from $\Theta_{\text {org }}$ values between $285 \mathrm{~K}$ and $320 \mathrm{~K}$ are from locations between $10^{\circ} \mathrm{S}$, $40^{\circ} \mathrm{N}, 60^{\circ} \mathrm{E}$, and $160^{\circ} \mathrm{E}$ (see grey box in Fig. 3 top). The origins of other trajectories are distributed in several different geographical regions (see Fig. 3 top).

The origins of trajectories from higher levels of potential temperature, from the $\Theta_{\text {org }}$ interval $320 \mathrm{~K}-360 \mathrm{~K}$, are concentrated around the Tibetan Plateau, Northeast China, Mongolia, Southeast Asia, and the Pacific Ocean. 55\% 
of these trajectories from $\Theta_{\text {org }}$ values between $320 \mathrm{~K}$ and $360 \mathrm{~K}$ are from locations between $0^{\circ} \mathrm{N}, 50^{\circ} \mathrm{N}, 60^{\circ} \mathrm{E}$, and $160^{\circ} \mathrm{E}$ (see grey box in Fig. 3 bottom). Also here, the origins of other trajectories are distributed globally (see

65 Fig. 3 bottom). Calculations of 60-day backward trajectories confirm that the origins of the air masses with enhanced values of tropospheric trace gases such as $\mathrm{CH}_{4}, \mathrm{CO}$, and $\mathrm{H}_{2} \mathrm{O}$ found in the region of interest during the TACTS flight on 26 September 2012 are mainly due to boundary source 70 emissions in Asia. 

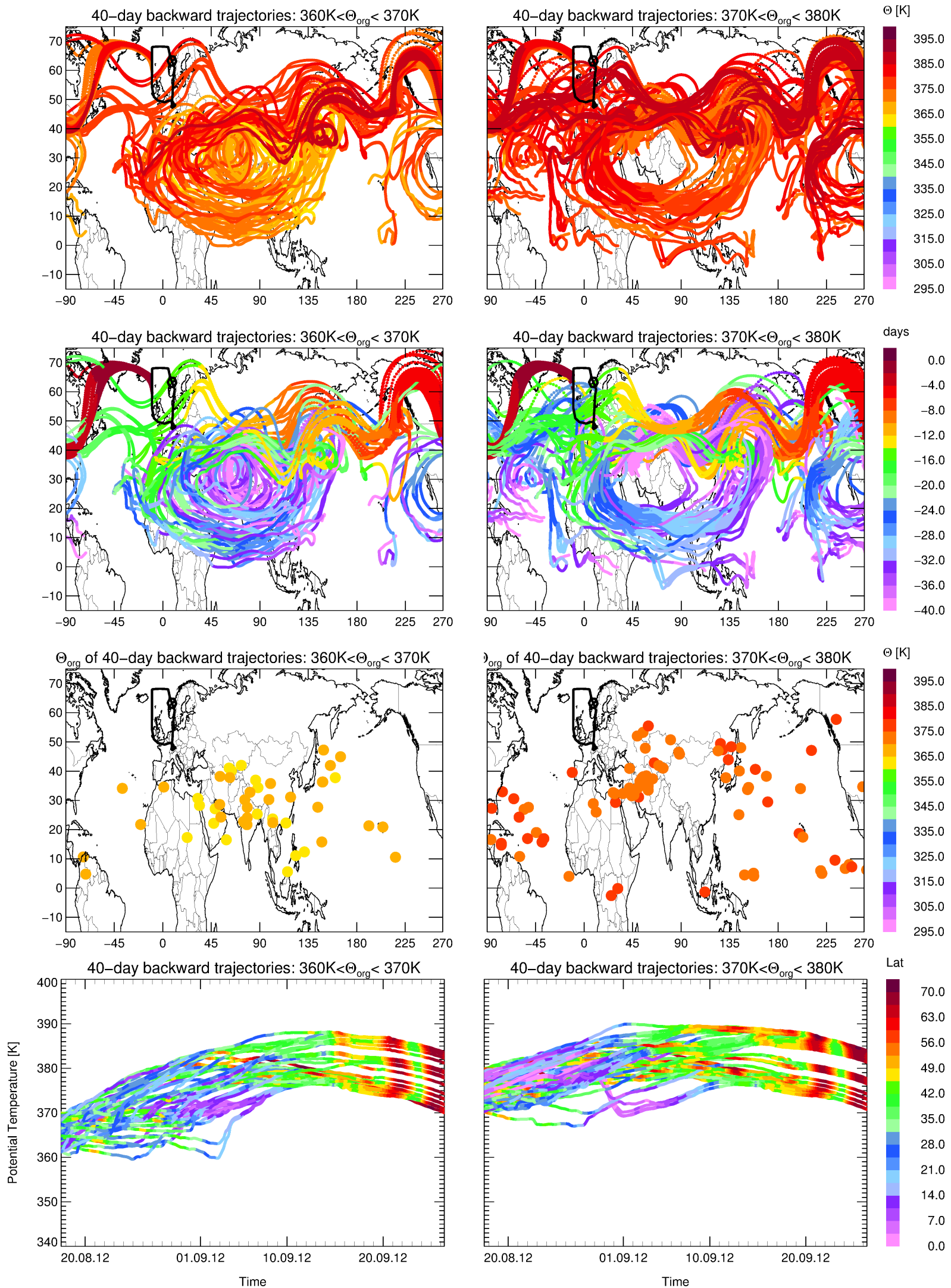

Fig. 1. Different 40-day backward trajectories for $\Theta_{\text {org }}$ intervals $360 \mathrm{~K}-370 \mathrm{~K}$ (left) and $370 \mathrm{~K}-380 \mathrm{~K}$ (right) are shown colour-coded by potential temperature (top) and by days reversed from 26 September 2012 (2nd row). Further, the geographical position of the origin of the 40-day backward trajectories $\left(\Theta_{\text {org }}\right)$ (3rd row) and potential temperature versus time along 40-day backward trajectories (bottom) are shown. Here, the colour indicates the latitude position of the trajectories. 

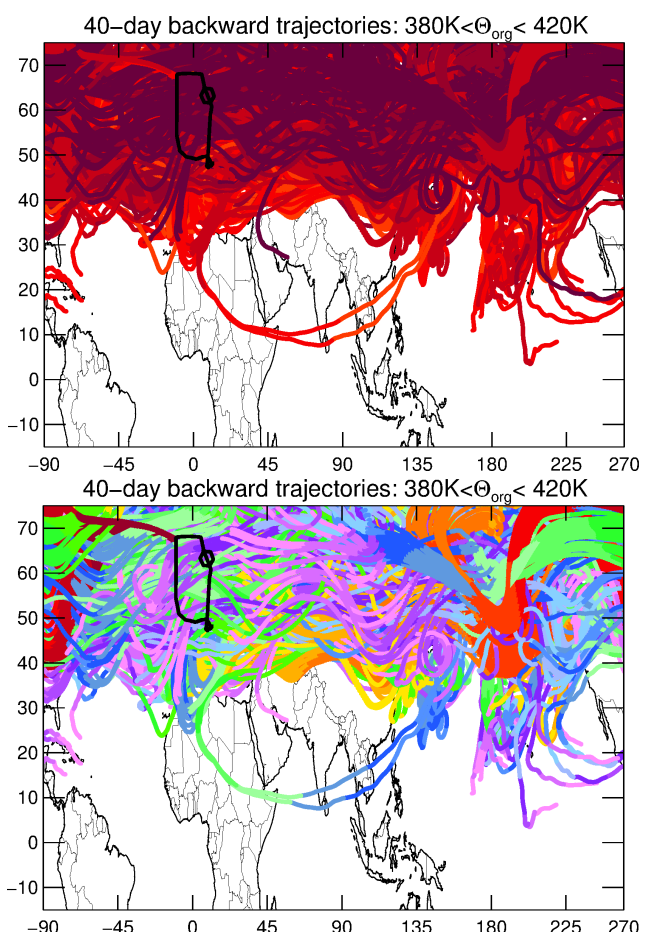

$\Theta_{\text {org }}$ of 40 -day backward trajectories: $380 \mathrm{~K}<\Theta_{\text {org }}<420 \mathrm{~K}$
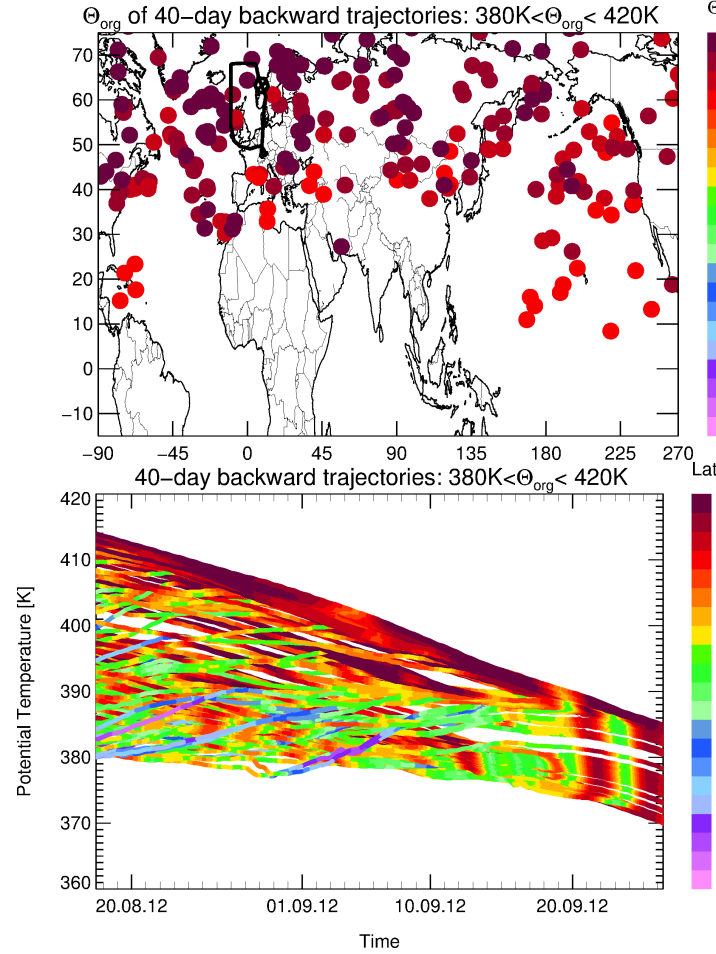

$\Theta[\mathrm{K}]$

395.0

385.0

375.0

365.0

355.0

345.0

335.0

325.0

315.0

305.0

295.0

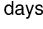

0.0

$-4.0$

$-8.0$

$-12.0$

$-16.0$

$-20.0$

$-24.0$

$-28.0$

$-32.0$

$-36.0$

$-40.0$

$\Theta[\mathrm{K}]$

395.0

385.0

375.0

365.0

355.0

345.0

335.0

325.0

315.0

305.0

295.0

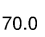

63.0

63.0

49.0

42.0

35.0

28.0

21.0

14.0

7.0

0.0

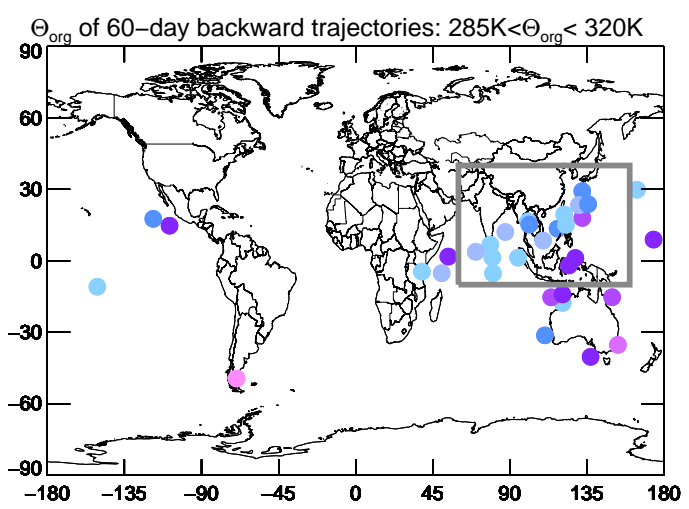

$\Theta[\mathrm{K}]$

385.0

375.0

365.0

355.0

345.0

335.0

325.0

315.0

305.0

295.0

285.0

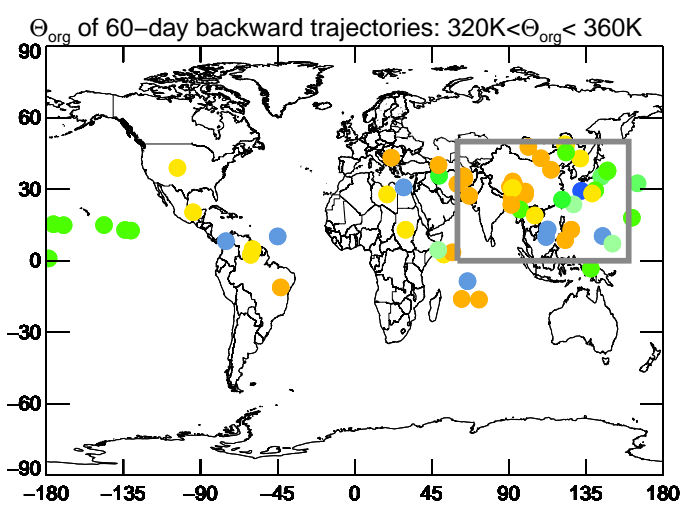

$\Theta[\mathrm{K}]$

385.0

375.0

365.0

355.0

345.0

335.0

325.0

315.0

305.0

295.0

285.0

Fig. 3. The geographical position of the origins of 60-day backward trajectories for trajectories starting in the region of interest (see Sect. 2 main body of the paper) for $\Theta_{\text {org }}$ between $285 \mathrm{~K}$ and $320 \mathrm{~K}$ (top) and between $320 \mathrm{~K}$ and $360 \mathrm{~K}$ (bottom). The grey box marks the region where the most origins are clustered.

Fig. 2. Same as figure 1, but for $\Theta_{\text {org }}$ interval $380 \mathrm{~K}-420 \mathrm{~K}$. 